
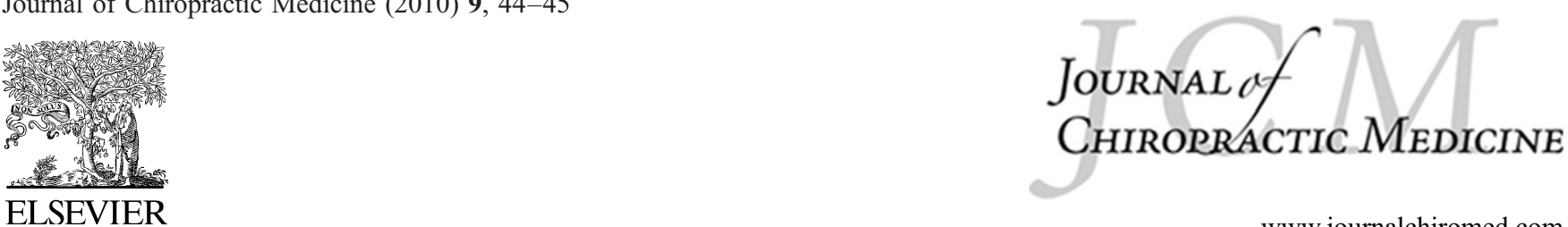

ELSEVIER

www.journalchiromed.com

\title{
News item
}

\section{Council on Forensic Sciences: an historical perspective}

Forensics is the science that deals with the application of medical facts to legal issues and/or proceedings. In chiropractic, most expert witnesses morphed from the ranks of diplomate programs that had little to no forensic components within their syllabi.

The National Board of Forensic Chiropractors (NBOFC) was created to promote competency in the chiropractic professional's ability to perform forensic activities. This corporation began offering classes in the field of chiropractic forensics in $1997 .{ }^{1}$

In 1998, the advisory executive board asked Steve Baker, DC, to investigate the requirements to achieve national accreditation in the field of chiropractic forensics. Based on this investigation, it became apparent that it would become necessary to form a separate nonprofit examination and certification organization. This entity would determine the job description for a forensic chiropractor, evaluate the credentials of applicants, administer specific examinations, and certify the successful completion of these activities as required by the National Organization of Credentialing Agencies.

This corporation (circa 2000) was named the International Board of Forensic Scientists and Examiners (IBOFSE) and was awarded nonprofit status. The goal was to award a certificate entitled Certified Independent Forensic Chiropractic Medical Examiner.

At the recommendation of legal counsel, the IBOFSE attempted to trademark this title to ensure unfettered usage of the title as required per national accrediting standards. The NBOFC preempted this endeavor and acquired a trademark for Certified Independent Forensic Chiropractic Medical Examiner. Subsequently, the president and CEO of the NBOFC stated that his goal was to acquire royalties for the use of this trademark. The IBOFSE determined that this would potentially disqualify the credentialing efforts under National Organization of Credentialing Agencies standards. On June 10,
2000, the president and CEO of NBOFC (for-profit) indicated that there "was a failure to develop volunteers or secure adequate financial resources to continue as a professional membership organization beyond 2000."

Therefore, per the recommendation of legal counsel, the IBOFSE applied for and received permission from the Arizona Corporation Commission for a name change to the American Board of Forensic Professionals (ABFP). The ABFP has received a service mark for a Diplomate of the American Board of Forensic Professionals (DABFP).

A forensics syllabus was formulated before 2000 . There was a concerted effort not to reinvent educational requirements that had been transcripted through recognized diplomate programs, but rather to use those hours (advanced standing toward core requirements) and to supplement where appropriate. Completion of these educational requirements (www.ChiroCredit.com) and passing the forensics-specific examination lead to certification as a forensic professional (DABFP). An example of such certification would be as follows: If one is a Diplomate of the American Board of Chiropractic Orthopedists (DABCO), one would be identified as a forensic professional concentrating in chiropractic orthopedics in legal matters.

On January 01, 2001, the Council on Forensic Sciences (CFS) was formed. The CFS is a not-for-profit professional organization that establishes and promotes educational and training parameters, improve skill sets, and encourage collaboration in the practice of forensics. The CFS provides graduate and postdoctoral needsbased and evidenced-influenced educational activities, training, tools, and technology recommendations to meet the current and future needs of the forensic examiner. The CFS recognizes the ABFP as its certifying board.

The CSF strives to offer courses leading to diplomate status, advocate current diplomates in other specialties 
to attain additional board certification in forensics, advocate that a core series of courses (similar to a master's degree core) be formulated and endorsed by all diplomate examining boards, systematically raise professional standards, be vigilant of developments in forensic science, and cooperate in a manner that reflects the interdisciplinary nature of forensic problem solving.

During 2001, the CFS worked aggressively to gain a seat in the American Chiropractic Association (ACA) House of Delegates (HOD). On August 30, 2002, the ACA HOD established the CFS as a College and subsidiary of the Council on Chiropractic Orthopedics (http://www.acatoday.org/content_css.cfm?CID=3622).

Past Presidents

2008-2009 Terrance M Eyerly, DC, DABFP

2007-2008 Max L Denton, DC, DABFP, DABCO

2006-2007 Thomas Ray, DC, DABFP, DABCOH

2005-2006 Steven G Baer, DC, DABFP, DABCOH

2004-2005 Richard Tesoriero, DC, DABFP

2002-2003 Clayton W Hopkins, DC, DABFP

2001-2002 Leanne N Cupon, DC, DABFP, DACRB

The CFS became the newest society to offer the Journal of Chiropractic Medicine as a membership benefit beginning with the journal's September 2009 issue. $^{2}$ The Journal of Chiropractic Medicine is a peerreviewed journal indexed in PubMed.

Effective October 01, 2009, the ACA HOD approved the elevation of the CFS to council status. Council status brings a greater voice for the CFS membership and will ensure increased awareness and education for forensic science in the chiropractic profession.
The CFS (http://www.forensic-sciences.org) offers education in forensic sciences for those interested in the field of forensics (ie, application of medical facts to legal issues and/or proceedings). This includes such topics as disability determination systems or programs, impairment rating systems, independent medical examinations, functional (work) capacity and physical assessment (federal) systems, return to work and fitness for duty (Department of Transportation [DOT]) assessment, fraud and abuse investigation, compliance issues, postpayment audits, ethics issues, documentation formulation, informed consent, and/or expert witness activities.

Leanne N. Cupon DC

Private Practice, Roswell, GA 30076

E-mail address: drlcupon@ix.netcom.com

Warren T. Jahn DC, MPS

Private Practice, Roswell, GA 30076

Terrance M. Eyerly DC

Private Practice, Hazelton, PA 18201

\section{References}

1. Fitzgerald P. The forensic chiropractic examiner, part I. Dynamic Chiropractic 2002;20(13).

2. Johnson C. The College on Forensic Sciences includes the Journal of Chiropractic Medicine as a membership benefit. J Chiropr Med 2009;8(3):A10. 